\title{
La gastronomía como producto de entretenimiento. Análisis de restaurantes y programas culinarios de éxito en España desde una perspectiva creativa
}

\author{
Gastronomy as an entertainment product. Analysis of restaurants and \\ successful cooking television shows in Spain from a creative perspective
}

\author{
Mgter. Eliseo RODRÍGUEZ-MONTEAGUDO ${ }^{1}$ \\ Universidad de Alicante (España) \\ eliseoromo@gmail.com \\ Dra. Tatiana HIDALGO-MARí ${ }^{2}$ \\ Universidad de Alicante (España) \\ tatianahidalgomari@gmail.com \\ DEA. Jesús SEGARRA-SAAVEDRA ${ }^{3}$ \\ Universidad de Alicante (España) \\ jesus.segarra@ua.es
}

\footnotetext{
${ }^{1}$ Máster en Comunicación e Industrias Creativas (2012) y Licenciado en Publicidad y Relaciones Públicas (2004) por la Universidad de Alicante. Doctorando (línea de investigación Comunicación en la era digital).

2 Doctora por la Universidad de Alicante (2013) y Máster en Comunicación e Industrias Creativas (2012). Miembro del grupo de investigación Industrias culturales hoy: producción, difusión, gestión y consumo de productos culturales en la era de la información (IIICCXXXI) de la UA. Participa en el proyecto I+D+i: La construcción social de la mujer en la ficción televisiva y la web 2.0: prototipos, recepción y retroalimentación (FEM2013-33411) financiado por el Ministerio de Economía y Competitividad.

${ }_{3}$ DEA (2008) y Licenciado en Publicidad y Relaciones Públicas (2005) por la Universidad de Alicante. Investigador y doctorando en Comunicación. Miembro del proyecto de investigación COMPUBES (Comunicación y Públicos Específicos) y Editor técnico adjunto de Revista Mediterránea de Comunicación de la UA.
} 


\section{Resumen}

La gastronomía está muy presente en la actual economía creativa. Tanto la televisión como las principales guías de crítica gastronómica están acercando la cultura gastronómica a un gran número de públicos, gracias a estrategias creativas que envuelven los productos vinculados al entorno creativo. Así pues, la cocina está ocupando cada vez más un lugar predominante como elemento sociocultural y económico. El presente artículo trata de profundizar en el nexo de unión entre la gastronomía, como fenómeno con alta carga cultural, y las Industrias Creativas, un sector dinámico cuyos modelos de negocio emplean la creatividad y el capital intelectual para generar productos y servicios con un valor añadido simbólico. Se pretende, pues, analizar la actual situación de la gastronomía y su constante aproximación a la sociedad del entretenimiento a través del estudio de múltiples actividades creativas gastronómicas, partiendo de los programas televisivos y restaurantes de éxito en España e identificando la tipología y finalidad de todas ellas. Para ello se realiza un análisis de casos de estudio tanto de programas de gastronomía en formato cooking show como de restaurantes 3 estrellas Michelín en España. Todo ello con el fin de establecer la evolución de la gastronomía como un modelo de Industria Creativa.

\section{Abstract}

Gastronomy is very present in today's creative economy. Both television and the main food critic guides are approaching the food culture to a large number of audiences, thanks to creative strategies involving linked products to creative environment. Thus, cooking is increasingly occupying a prominent place as a sociocultural and economic element. This article attempts to explore the link between gastronomy, considered as a phenomenon with a high cultural influence, and the Creative Industries, a dynamic sector whose business models use creativity and intellectual capital to create products and services with a symbolic added value. It therefore aims to analyze the current situation of gastronomy and the non-stop approach to social entertainment through the study of multiple gastronomic creative activities, based on television programmes and successful restaurants in Spain and identifying the type and purpose of all of them. With this aim, an analysis of studies of both gastronomy programmes as cooking show format and some 3 Michelin star restaurants in Spain is carried out. All this, in order to establish the evolution of gastronomy as a model of Creative Industry.

Palabras Clave: Branding; comunicación; cooking show; cultura; gastronomía; Industrias Creativas.

Key Words: Branding; communication; cooking show; culture; gastronomy; Creative Industries.

\section{Introducción}

\subsection{Gastronomía y creatividad}

Facultad de Ciencias de la Información - Universidad de La Laguna

Avenida César Manrique, s/n; Campus de Guajara

38071 La Laguna, Tenerife (Islas Canarias - España) 
La gastronomía se ha convertido, especialmente durante la última década en España, en una temática de gran interés para numerosos públicos que conforman la actual sociedad del entretenimiento. En este sentido, la aparición incesante de distintos programas de televisión con suculentas audiencias y el amplio abanico de restaurantes que aumentan en reconocimientos y número de premios de carácter internacional son una buena muestra de ello. Es evidente que esta sinergia está contribuyendo a reforzar las marcas-territorio, gracias a la promoción y expectación que generan sobre ellas y, por tanto, refuerza también a la propia economía creativa en España.

Dado este auge, casi de forma natural, están surgiendo otras estrategias de negocio paralelas que intentan ampliar dicho impulso más allá de la propia oferta culinaria o contenido televisivo. Todas ellas, evidentemente, tienen como motor la creatividad. Y es que en este sentido es lógico que "ante la profusión de unos mismos conocimientos compartidos por una multitud de empresas, se recurra a la capacidad creativa de las personas y, por extensión, a la de las compañías para explotar de manera original esos conocimientos" (Morcillo, 2005: 18).

La gastronomía, pues, pasa a convertirse en un interesante objeto de estudio directamente relacionado con el sector más creativo, representado en este caso por las Industrias Creativas. Un término de actualidad que se emplea para catalogar modelos de negocio emergentes en los que la creatividad se encuentra presente en todas sus fases para aproximar el producto/servicio al receptor mediante múltiples formas y formatos.

Estas actividades se dirigen a la actual sociedad de ocio y entretenimiento, que se caracteriza por demandar un valor simbólico en el contenido tradicional. Representan, pues, las Industrias Creativas una singular forma de canalizar una serie de productos y servicios creativos hacia un mercado en el que el consumidor exige un poco más. "El nuevo consumidor ya sabe que los mejores productos y las mejores marcas no tienen que hacer publicidad para gozar de esa consideración" (Olivares, 2012: 56).

Por tanto las Industrias Creativas, aunque no descartan la publicidad convencional, recurren a la amplificación y ramificación de actividades para promocionar su marca a través de otros productos y servicios. Por ello, la gastronomía encaja de forma lógica, ya no sólo por el modo de producción sino también de venta. $Y$ es que en cada una de estas fases, la creatividad junto con la autoría aportan un valor adicional y distintivo al producto tradicional, convertido ahora en producto cultural. 


\subsection{Restauración y programas de televisión gastronómicos}

España ha sido siempre un país ligado a la gastronomía. Las variedades culturales, geográficas y climáticas que componen su territorio ha dotado al país de magníficos espacios caracterizados por la amplia variedad gastronómica y la alta calidad de sus productos. De igual modo, los restaurantes, como transformadores de esa materia prima, también se han convertido en embajadores de marca.

De hecho, algunos como El Bulli o el Séller Can Roca han sido reconocidos como mejores restaurantes del mundo por The World's 50 Best Restaurants ${ }^{4}$ y por ello se consideran como una auténtica referencia de la cocina internacional. $Y$ es que este ranking se realiza mediante una votación que se rige por unas reglas muy concretas especificadas en un manifiesto que convierten a dicha lista resultante "en un ranking único, no comparable con ninguna otra guía o referente culinario" (Manifiesto Premios S. Pellegrino a los 50 mejores restaurantes del mundo, consulta 2014). De igual modo, en el 2014 otros restaurantes de España también han sido incluidos en este ranking de los mejores 50 de todo el mundo, corroborando así el buen momento de nuestra gastronomía.

Además otros muchos restaurantes siempre han estado reconocidos por la prestigiosa Guía Michelín ${ }^{5}$, una guía de referencia internacional que reconoce también la buena labor de todas las cocinas del mundo.

Siguiendo con esta línea, la televisión desde sus inicios, España también ha trasladado a las audiencias la cultura gastronómica a través distintos formatos. Desde Mesa y mantel (TVE 1, 1958) o Con las manos en la masa (TVE 1, 1984-1991) hasta los coetáneos MasterChef (TVE 1, 2013-), Top Chef (Antena 3, 2013-), Pesadilla en la Cocina (La Sexta, 2012-2014) o Deja sitio para el postre (Cuatro, 2014), la televisión ha emitido distintos formatos culinarios para aproximar la profesionalización de la cocina a la sociedad a través del entretenimiento. De esta forma también ha dotado a las respectivas cadenas emisoras de un formato de éxito aparentemente garantizado. En la actualidad, tal y como afirman Hidalgo y Segarra

Se vive un cambio de paradigma que desplaza el mensaje esencial y la finalidad del programa de cocina instructivo (dirigido a aquellos que querían aprender a cocinar) a una intención mucho más expectativa, de entretenimiento en la que, al

\footnotetext{
${ }^{4}$ Guía internacional que nombra anualmente los 50 mejores restaurantes del mundo. http://www.theworlds50best.com/

${ }^{5}$ La guía MICHELIN España \& Portugal ha seleccionado en 20148 restaurantes con tres estrellas, 19 restaurantes con dos estrellas y 144 restaurantes con una estrella.
} 
fin y al cabo, lo importante es distraerse, evadirse y no tanto recibir la formación culinaria (Hidalgo y Segarra, 2014:13)

Por tanto, no es de extrañar que los programas culinarios actualmente apuesten más por un estilo Avant Garde food Shows ${ }^{6}$, basados en el formato concurso y orientado sobre todo al entretenimiento.

Por todo ello, queda patente la importancia de la gastronomía como actividad de promoción y de engranaje sociocultural en España en las últimas décadas. Una tendencia que paulatinamente va ampliando no sólo la tipología de públicos sino también el número y modos de canales creativos para llegar a todos ellos.

\section{3. La gastronomía como Industria Creativa}

El término Industrias Creativas (II.Creativas) adquiere importancia a finales de los años $90^{7}$ para atender a las actividades dentro de la economía creativa. Un sector multidisciplinar, más allá de la tradicionales Industrias Culturales, que engloba actualmente una amplia gama de actividades caracterizadas por la creatividad en todas sus fases, desde el diseño hasta la comercialización de bienes tanto tangibles como intangibles.

Las II. Creativas se mueven en un terreno maleable, flexible, líquido (gaseoso diríamos, ahora, si consideramos la nube telemática donde se exhiben, circulan, se comparten, se modifican y se venden sus productos), que borra las fronteras entre lo económico y lo estético, lo material y lo simbólico, lo privado y lo público, lo local y lo global, el ocio y el negocio, el productor y el consumidor, el juicio del experto y la opinión del amateur, incluso el contenido profesional y el generado por el propio usuario (Rodríguez, Tur y Olivares, 2010: 7).

Ante este contexto, las Industrias Creativas continúan en un proceso de asentamiento en la actual sociedad ${ }^{8}$, y con diversas definiciones ${ }^{9}$ desde los organismos institucionales. No obstante presentan una serie de particularidades que las definen. Son una serie de parámetros que ayudan a identificar y a acotar las distintas actividades que las conforman. Así pues las II. Creativas "Son los ciclos de creación, producción y distribución de los bienes

\footnotetext{
6 Término extraído de la clasificación que realiza Ketchum, C. (2005) para catalogar a los programas culinarios de telerrealidad.

${ }^{7}$ Mapping the Creative Industries: A Toolkit British Council 2010

${ }^{8}$ Garnham, N. (2005) From cultural to creative industries. An analysis of the implications of the "creative industries" approach to arts and media policy making in the United Kingdom. International Journal of Cultural Policy, Vol. 11, No. 1, 2005

${ }^{9}$ DCMS (1998), UNESCO (2006), UE (2010), UNCTAD (2008-2010).
} 
y servicios que tienen como base fundamental la Creatividad y el capital intelectual" (UNCTAD, 2010: 34).

Entre la clasificación de la UNCTAD podemos encontrar múltiples actividades creativas de capital intelectual agrupadas en cuatro grandes bloques: "patrimonio cultural", "artes", "medios de comunicación" y "creaciones funcionales". En esta caso, se podría incluir el formato programa gastronómico de televisión en el bloque de medios y, por otra parte, en función del tipo de cocina de cada restaurante, podrían clasificarse en el primer bloque, si se trata de una cocina tradicional entendida como un tipo de expresión cultural tradicional, servicio recreacional-cultural, o en su caso, en el de servicios creativos, si hablamos propiamente de un estilo sustentado sobre I+D como es el caso de los restaurantes de vanguardia. Por tanto queda patente que "El concepto de industrias creativas se hace operativo mediante la elaboración de una lista de actividades en las cuales la creatividad tiene especial importancia" (Boix, 2011:186).

Por tanto, los programas de televisión representarían un producto intangible mientras que la oferta culinaria de cada restaurante sería de carácter tangible. Todos ellos con una autoría y un valor simbólico añadido. Sea como sea, incluso puede ser oportuno considerar la gastronomía propiamente como un modelo más de Industria Creativa, ya que durante todas sus fases la creatividad resulta fundamental y aporta un aspecto distintivo a una actividad particular y específica.

Es evidente que la gastronomía puede formar parte de ese conjunto de actividades, ya que desde la fase de creación hasta la promoción de dichos resultados precisan de un alto nivel de creatividad. Especialmente cuando se trata de programas televisivos que intentan destacar en la parrilla 0 , por otra parte, los restaurantes que intentan formar parte de los más destacados del panorama español y/o internacional. En todos los casos y sus respectivas actividades, el componente creativo resulta fundamental para garantizar la calidad, diferenciación y disfrute, por tanto también como experiencia de marca. "La marca puede entenderse muchas veces como una relación. En este sentido, cada vez que un miembro de uno de los grupos de interés interactúa con una organización, esta experiencia contribuye a la percepción positiva o negativa de la misma" (Pérez y Salinas, 2008: 24).

En ambos casos, tanto en televisión como en los restaurantes presentes en guías internacionales, se generan actividades multidisciplinares adicionales que suelen generar otra serie de productos/servicios que son comercializados y comunicados de forma creativa. 
El objetivo es mantener y prolongar el éxito del modelo base y englobar todas estas acciones bajo una misma marca, que además de potenciar su propia difusión, traslada su esencia a cada una de las distintas actividades. En este sentido las marcas

Representan la suma de todas las acciones y valías corporativas, mucho más allá del propio bien o servicio presentado con una identidad visual determinada. Constituyen a día de hoy una perfecta síntesis de la empresa o institución en todas sus facetas y dotan de mayor significado a cualquier actividad resultante de ella (Rodríguez e Hidalgo, 2013: 146).

\section{Metodología}

\subsection{Objetivos}

Ante este momento emergente de la gastronomía, el presente estudio pretende realizar una aproximación a las distintas formas de acercar la cocina a la sociedad del entretenimiento, siempre intentando identificar en todas ellas los principales elementos definitorios de las Industrias Creativas.

Se pretende analizar la ramificación creativa-mediática de restaurantes premiados y programas gastronómicos televisivos líderes en España, intentando identificar tales estrategias mediante el estudio de casos significativos. Se trata de abordar las nuevas tendencias gastronómicas a través del análisis de contenido de los ejemplos seleccionados y especialmente mediante su potencial para difundir acciones con valor añadido simbólico.

Por tanto los principales objetivos del presente proceso investigador son los siguientes:

1. Analizar el auge de la gastronomía como Industria Creativa.

2. Establecer un grupo de programas de televisión y restaurantes relevantes en el panorama gastronómico de España como ejemplos de dichas tendencias.

3. Identificar actividades multidisciplinares creativas de los casos de estudio.

4. Determinar la función y las aportaciones de dichas actividades a los programas y restaurantes así como también a las respectivas marcas.

5. Establecer los principales canales de promoción tanto de la actividad principal como de las secundarias.

6. Valorar la utilización de los recursos creativos en el desarrollo de la estrategia de comunicación. 
En este sentido, las premisas de partida de las que parte el estudio son las siguientes:

- Los programas de televisión basados en la gastronomía así como los restaurantes con Estrellas Michelín en España forman parte de las Industrias Creativas.

- Los programas de televisión gastronómicos y los restaurantes con algún tipo de reconocimiento de carácter internacional en España desarrollan otras actividades creativas adicionales a su cometido principal. A su vez, el contenido televisivo y la oferta culinaria de los restaurantes, desarrollan otras acciones creativas paralelas que ayudan a promocionar las respectivas marcas de cada caso de estudio.

- Dichas actividades adicionales tienen un carácter promocional que completa de forma multidisciplinar el contenido del programa y la oferta del restaurante, según cada caso, con acciones dirigidas principalmente a garantizar el ocio y el entretenimiento del receptor.

\subsection{Proceso metodológico}

Atendiendo a todo lo expuesto, el estudio presenta un análisis cuantitativo y cualitativo de contenido de información corporativa online, principalmente presente en las respectivas Webs oficiales (información abierta y pública, incluida tienda online y documentación de descarga sin necesidad de registro) de los casos de estudio seleccionados. Por lo que respecta a los programas de televisión, también se extraerán información a través de los propios contenidos emitidos por las cadenas durante el 2013 y el 2014.

En este caso, puesto que lo que se pretende es comparar programas de gastronomía con restaurantes con 3 estrellas Michelín, el criterio de selección de los casos de estudio será a través de un muestreo no probabilístico estratégico para determinar programas de televisión de éxito. Por su parte, la selección de los restaurantes se basa en la el listado de todos los restaurantes catalogados con 3 estrellas Michelín en España.

En el caso de los programas de televisión se seleccionarán dos talent shows de éxito, MasterChef y Top Chef, ambos con una estructura y dinámica muy similar, que permita establecer diferencias o paralelismos. Asimismo, por lo que respecta a los establecimientos de restauración, se seleccionarán todos los restaurantes en España calificados con 3 estrellas Michelín durante el 2014. De este modo se pretende, por una parte, analizar casos 
de notable éxito, y por otra, poder determinar si tanto dichos programas gastronómicos como los restaurantes estrellas Michelín en España recurren realmente a otras actividades creativas para canalizar su labor y llegar a un público más amplio a través de vías dirigidas al entretenimiento. Por lo tanto, el análisis de contenido se centra sobre dos ejes principales:

1. Modelo base: programas de televisión y restaurantes Guía Michelín España. Contempla programas gastronómicos de formato talent show y los restaurantes 3 estrellas Michelín seleccionados en el 2014.

2. Productos y actividades multidisciplinares partiendo del modelo base: libros, aplicaciones, juegos, DVD, tienda online, montajes audiovisuales, moda, otros servicios...

Adicionalmente a los casos de estudio, los análisis también se centrarán en otras actividades creativas más allá de los contenidos televisivos y la oferta culinaria de los respectivos restaurantes.

\section{Diseño variables de estudio}

Atendiendo a los objetivos planteados y la metodología seleccionada, se han diseñado una serie de variables y categorías cerradas, principalmente de carácter nominal, para poder llevar a cabo dicho análisis de forma apropiada.

Se pretende de esta forma realizar una aproximación exhaustiva a los casos de estudio, extrayendo la mayor cantidad de información que permita conocer de cerca los objetos de análisis desde la perspectiva de las Industrias Creativas.

De este modo se intentará recopilar información en torno a:

Tabla 1. Objeto de análisis y objetivos

\begin{tabular}{|l|l|}
\hline \multicolumn{1}{|c|}{ Objeto de análisis } & \multicolumn{1}{c|}{ Objetivo } \\
\hline Página Web & Extraer toda la información actualizada de carácter oficial. \\
\hline Actividad principal & $\begin{array}{l}\text { Determinar si se trata de un programa de televisión o } \\
\text { restaurante. }\end{array}$ \\
\hline Año de fundación & Conocer la trayectoria. \\
\hline Antecedentes & $\begin{array}{l}\text { Clarificar si el programa es una adaptación de un formato } \\
\text { existente o si el restaurante es de origen familiar. }\end{array}$ \\
\hline Otros programas/restaurantes & $\begin{array}{l}\text { Establecer si el programa de televisión dispone de otras } \\
\text { versiones en España o si el restaurante cuenta con otros } \\
\text { establecimientos adicionales. }\end{array}$ \\
\hline
\end{tabular}




\begin{tabular}{|l|l|}
\hline Otras actividades creativas & $\begin{array}{l}\text { Comprobar si el programa o restaurante desarrolla otras } \\
\text { actividades creativas adicionales al cometido principal. }\end{array}$ \\
\hline $\begin{array}{l}\text { Tipología otras actividades } \\
\text { creativas }\end{array}$ & Identificar el carácter de dichas actividades creativas. \\
\hline $\begin{array}{l}\text { Finalidad otras actividades } \\
\text { creativas }\end{array}$ & $\begin{array}{l}\text { Analizar las aportaciones de las actividades creativas } \\
\text { adicionales hacia el programa o restaurante. }\end{array}$ \\
\hline Medios de promoción & $\begin{array}{l}\text { Enumerar los principales canales de promoción: } \\
\text { Programas de cocina: se analizará la Web oficial así } \\
\text { como el contenido emitido por la cadena emisora } \\
\text { (tanto en el propio programa como en los spots). } \\
\text { Restaurantes: se analizará la Web oficial (incluido si } \\
\text { presenta departamento o noticias de prensa). }\end{array}$ \\
\hline $\begin{array}{l}\text { Tienda online actividades } \\
\text { creativas adicionales }\end{array}$ & $\begin{array}{l}\text { Comprobar si las respectivas Webs oficiales incorporan } \\
\text { tiendas online para poder adquirir productos resultantes de } \\
\text { las actividades creativas adicionales. }\end{array}$ \\
\hline
\end{tabular}

Fuente: elaboración propia

Variables y categorías

A continuación se expone las variables de análisis resultantes y las correspondientes categorías:

Tabla 2. Variables y categorías de estudio

\begin{tabular}{|c|c|c|}
\hline $\begin{array}{c}\text { № } \\
\text { Variable } \\
\end{array}$ & Variable & Categorías \\
\hline P1 & ¿Dispone de página Web corporativa oficial? & $\begin{array}{l}\text { 1. Sí } \\
\text { 2. No }\end{array}$ \\
\hline $\mathrm{P} 2$ & ¿Cuál es la actividad principal? & $\begin{array}{l}\text { 1. Programa de televisión } \\
\text { 2. Restauración }\end{array}$ \\
\hline P3 & $\begin{array}{l}\text { ¿Cuál es el primer año de emisión o de } \\
\text { fundación? }\end{array}$ & $\begin{array}{l}\text { 1. Años } 60 \\
\text { 2. Años } 70 \\
\text { 3. Años } 80 \\
\text { 4. Años } 90 \\
\text { 5. } 2000 \text { en adelante } \\
\text { 6. No disponible }\end{array}$ \\
\hline$\overline{P 4}$ & $\begin{array}{l}\text { ¿El programa está basado en un formato } \\
\text { existente? ¿El restaurante es de origen familiar? }\end{array}$ & $\begin{array}{l}\text { 1. Sí } \\
\text { 2. No/no consta }\end{array}$ \\
\hline P5 & $\begin{array}{l}\text { ¿Ha derivado el programa en otros subformatos } \\
\text { o cuenta el restaurante con otros } \\
\text { establecimientos? }\end{array}$ & $\begin{array}{l}\text { 1. Sí } \\
\text { 2. No/no consta }\end{array}$ \\
\hline $\mathrm{P6}$ & ¿Desarrolla otras actividades creativas & 1. Sí \\
\hline
\end{tabular}




\begin{tabular}{|c|c|c|}
\hline & adicionales para potenciar el modelo base? & 2. No \\
\hline P8 & ¿Cuál es la finalidad de dichas actividades? & $\begin{array}{l}\text { 1. Informar/comunicar/divulgar (libros, revistas, cine/vídeo, } \\
\quad \text { pintura y exposiciones) } \\
\text { 2. Investigar (I+D) } \\
\text { 3. Aumentar visitas (turismo enológico) } \\
\text { 4. Ampliar marca (diseño, joyería y moda) } \\
\text { 5. Participar (software app y otros juegos) } \\
\text { 6. Combinación de varias }\end{array}$ \\
\hline P9 & $\begin{array}{l}\text { ¿Qué medios emplea para promocionar todo el } \\
\text { proyecto? }\end{array}$ & $\begin{array}{l}\text { 1. Internet } \\
\text { 2. Televisión } \\
\text { 3. Prensa } \\
\text { 4. Internet y televisión } \\
\text { 5. Internet y labor mediática (difusión en diversos medios) }\end{array}$ \\
\hline P10 & ¿Dispone de tienda online? & $\begin{array}{l}\text { 3. Sí } \\
\text { 4. No }\end{array}$ \\
\hline
\end{tabular}

Fuente: elaboración propia

Siguiendo los criterios anteriormente expuestos, los casos de estudio que se presentan identifican también las tendencias gastronómicas creativas en España. Los niveles de audiencia como el reconocimiento internacional gastronómico dejan muestra de ello.

Los casos de estudio en televisión son representativos del talent show: MasterChef y Top Chef. Y los ocho restaurantes elegidos coinciden en tener 3 estrellas Michelín.

\section{MasterChef}

Se trata de un talent show en el que 15 chef amateur compiten por ganar el concurso y conseguir un gran premio. Consta de un jurado compuesto por reconocidos chef. En España se ha emitido hasta la fecha en 2013 y 2014. 
Además de la buena acogida por parte de la audiencia cuenta con los siguientes premios: Premio Ondas (2013), Bronce en III Lovie Awards (2013), Premio de la Crítica en el FesTVal (2013), Men's Health Hombre del Año (2013), Premio ¡Bravo! Televisión (2014), Premio 5 al dia (2014) y Premio Zapping (2014) ${ }^{10}$.

\section{$\underline{\text { Top Chef }}$}

Top Chef es otro talent show, en este caso únicamente para profesionales, en el que los participantes compiten por convertirse en el Top Chef del país. En España se ha emitido en el 2013 y 2014, tras el éxito de audiencia cosechado en la edición anterior.

En relación a los datos de audiencia registrados en las respectivas finales más recientes de ambas ediciones, se constata el éxito de los formatos:

- Master Chef, final edición 2014: 25\% de share y 3.173 .000 espectadores ${ }^{11}$.

- Top Chef, final edición 2013: 23,9\% de share y 3,8 millones de espectadores ${ }^{12}$.

\section{Restaurantes con tres estrellas Michelín en 2014}

De origen francés, la Guía Michelín se encarga de evaluar anualmente los principales restaurantes de la geografía española con 3, 2 y 1 estrella mediante visitas de inspectores expertos en turismo a los establecimientos de interés.

Por lo que respecta a los restaurantes, se toman como casos de estudio los 8 calificados con 3 estrellas en el 2014 por "Cocina excepcional, mesa que justifica el viaje" (Dossier prensa Guía Michelín, 2014: 1).

Tabla 3. Establecimientos 3 estrellas Michelín España 2014

\begin{tabular}{|c|c|c|c|c|}
\hline Caso de estudio & Ciudad & Provincia & Establecimiento & Chef \\
\hline $\mathrm{n}^{\circ} 3$ & Denia & Alicante & Quique Dacosta & Quique Dacosta \\
\hline $\mathrm{n}^{\circ} 4$ & $\begin{array}{c}\text { Donostia-San } \\
\text { Sebastián }\end{array}$ & Guipúzcoa & Akelare & PedroSubijana \\
\hline n 5 & Donostia-San & Guipúzcoa & Arzak & Juan Mari y Elena \\
\hline
\end{tabular}

\footnotetext{
${ }^{10}$ Fuente: Web de MasterChef http://www.rtve.es/television/masterchef/ Consultado en septiembre de 2014.

${ }^{11}$ Fuente: http://www.rtve.es/

${ }^{12}$ Fuente: http://www.antena3.com/
} 


\begin{tabular}{|c|c|c|c|c|}
\hline & Sebastián & & Arzak \\
\hline $\mathrm{n}^{\circ} 6$ & Girona & Girona & $\begin{array}{c}\text { El Celler de Can } \\
\text { Roca }\end{array}$ & Joan y Jordi Roca \\
\hline $\mathrm{n} \div 7$ & Larrabetzu & Vizcaya & Azurmendi & Eneko Atxa \\
\hline $\mathrm{n}^{\circ} 8$ & Lasarte-Oria & Guipúzcoa & Martín Berasategui & $\begin{array}{c}\text { Martín } \\
\text { Berasategui }\end{array}$ \\
\hline $\mathrm{n}^{\circ} 9$ & Madrid & Madrid & Diverxo & David Muñoz \\
\hline $\mathrm{n}^{0} 10$ & Sant Pol de Mar & Barcelona & Sant Pau & $\begin{array}{c}\text { Carme } \\
\text { Ruscalleda }\end{array}$ \\
\hline
\end{tabular}

Fuente: Dossier prensa Guía Michelín España y Portugal 2014 


\section{Resultados}

Tras el análisis realizado (finalizado el 13 octubre de 2014), se detalla a continuación la interpretación de los datos obtenidos en función de cada una de las variables analizadas.

\section{Página Web}

Todos los casos analizados disponen de Web corporativa con amplia información con una estructura sencilla y comprensible.

\section{Actividad principal}

Dado el cometido principal de los 2 programas de televisión y 8 restaurantes analizados así como el componente creativo durante todo el proceso de sus actividades, unido a la autoria y el valor simbólico de todas ellas, y sumado a los distintos reconocimientos, se constata que todos los casos analizados forman parte de las Industrias Creativas en España. Por lo tanto, en relación a los parámetros principales definitorios de las II.Creativas no sólo cumplen dichos requisitos, sino que además desarrollan otra serie de actividades creativas que a continuación también se analizan.

Año de fundación

Los programas de televisión son actuales y recientes. En el caso de los restaurantes hay una gran trayectoria que les precede. Mientras que los formatos televisivos estudiados datan del 2013, gran parte de los restaurantes analizados con 3 estrellas Michelín gozan de una amplia historia. No obstante, algunos de los restaurantes analizados no ofrecen esta información al respecto.

Asimismo, en relación también a los restaurantes, tienden a concentrarse en zonas geográficas concretas. De los 8 casos, 4 están ubicados en el País Vasco, 1 en Madrid y 3 en la costa mediterránea. Estos datos demuestran la amplia cultura culinaria de estos territorios. 
Antecedentes

\section{Gráfico 1. Antecedentes programas/origen familiar restaurantes}

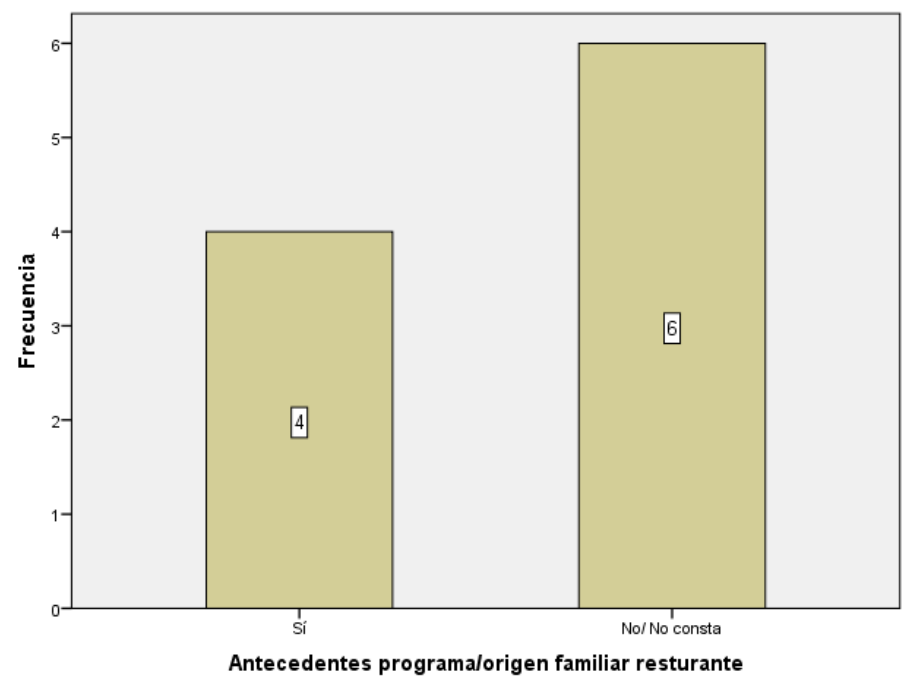

Fuente: elaboración propia

Entre los casos de estudio analizados, 4 de ellos tienen un origen previo. En el caso de los programas de televisión ambos son una adaptación de un formato original ya emitido en otro país.

Por su parte, 2 de los restaurantes tienen su punto de partida en generaciones anteriores y son un buen ejemplo de la evolución y adaptación de dicho modelo de negocio a la demanda de los nuevos tiempos. No obstante, en el caso de los restaurantes también parece claro que el hecho de alcanzar el éxito internacional no necesariamente debe ir ligado a una historia o trayectoria familiar previa, pues los otros 6 restantes no son de origen familiar (o al menos, no se especifica como tal en los respectivos sitios Web oficiales). 
Otros programas/restaurantes

Gráfico 2. Otros programas o restaurantes

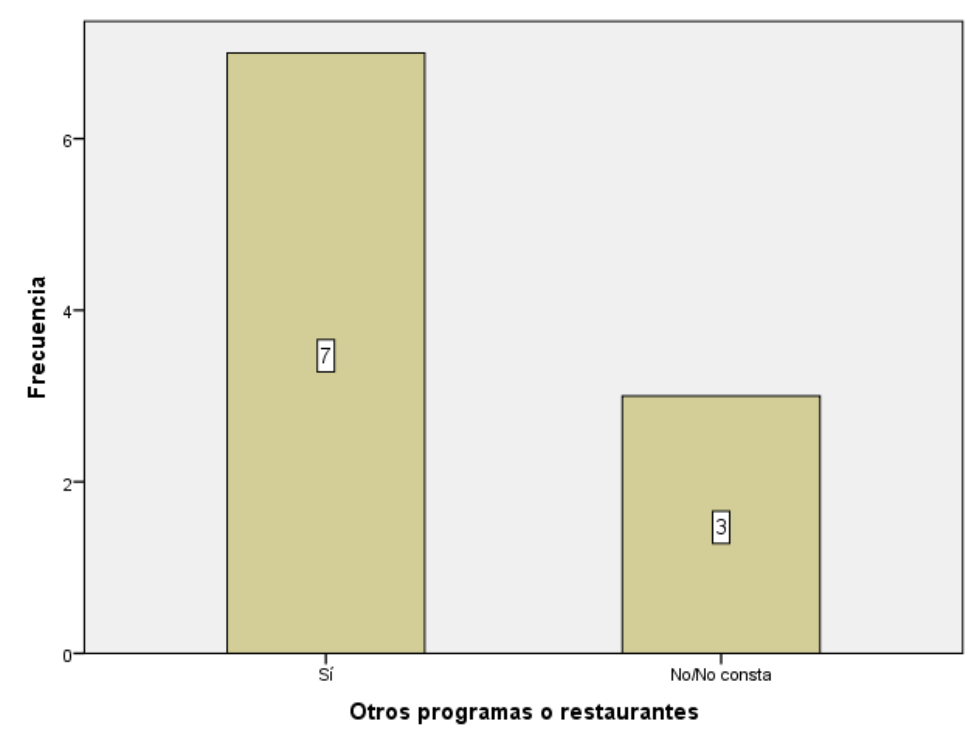

Fuente: elaboración propia

En sentido inverso, existen algunos de los casos han sido también precursores y han generado otras actividades similares. En concreto, MasterChef España ha inspirado otro formato televisivo: MasterChef Junior. Un programa con la misma dinámica y estructura pero dirigido a niños. Se trata de un talent infantil con participantes entre 8 y 12 años.

En el caso de los restaurantes, 6 de ellos (Arzak, Azurmendi, El Celler de Can Roca, Martín Berasategui Quique Dacosta y Sant Pau) cuentan con otros establecimientos de restauración además del galardonado con 3 Estrellas Michelín (incluso alguno en otros países). Aspecto que demuestra también el carácter emprendedor y propiamente creativo de sus propietarios para diversificar el modelo de negocio y seguir expandiendo la firma.

Tipología otras actividades creativas

Tanto los programas de televisión como los propios restaurantes desarrollan otras actividades creativas adicionales a la principal (no se tiene presentes para el estudio otras actividades como caterings, asesoramiento, celebración de eventos, etc.). En este sentido todos los casos analizados complementan su actividad principal con otra serie de acciones 
accesorias creativas (gráfico 3) que amplifican dicha tarea. De esta forma queda patente la promoción de los programas y restaurantes mediante otros canales creativos.

Asimismo, atendiendo a los resultados obtenidos, se observa también que algunos de los casos de estudio emplean únicamente una sola actividad adicional a la principal mientras que otros combinan varias de ellas. Entre todas ellas, la edición de libros es la más recurrente, bien de forma aislada o combinada. La fórmula conjunta de publicación de libros y revistas, así como el uso de aplicaciones participativas online, son estrategias empleadas principalmente por los programas de televisión. Por otra parte, la edición de libros junto con material audiovisual ${ }^{13}$ en formato cine y/o vídeo (Sant Pau) es otro modelo recurrente empleado por los restaurantes. Otros casos emplean todas estas actividades conjuntamente con otras trasversales como la edición de perfumes, cubiertos en formato joya, juegos o incluso exposiciones (El Celler de Can Roca).

\section{Gráfico 3. Tipología otras actividades adicionales de Industrias Creativas}

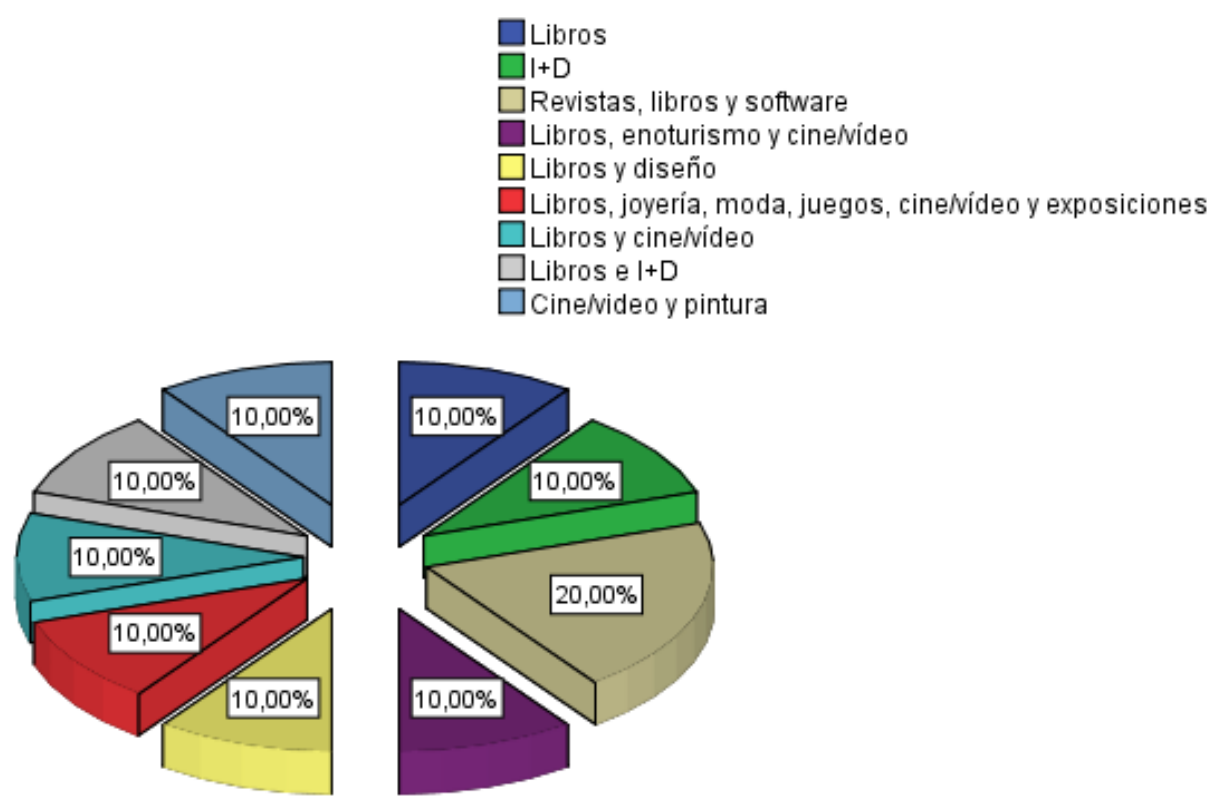

Fuente: elaboración propia

\footnotetext{
${ }^{13}$ El material audiovisual presente en las páginas Web de los programas culinarios se ha considerado como una prolongación del mismo por constituir principalmente fragmentos del propio formato televisivo.
} 
Como se puede observar, la tipología de las actividades creativas adicionales es muy amplia y variada. Entre el resto de actividades aparecen otras como I+D, pintura (gastronómica) o el turismo enológico. Esta amplia tipología de actividad reafirma también el carácter multidisciplinar de la gastronomía a la hora de aproximarse a sus distintos públicos. Distintas fórmulas que comercializan un determinado producto o servicio a la vez que promocionan el propio programa de televisión o restaurante. Asimismo posibilitan ampliar el abanico de público más allá de la propia audiencia del programa o cliente de un restaurante. De este modo, lectores, usuarios de aplicaciones, interesados por la investigación, seguidores de moda y del arte... se convierten en nuevos receptores gastronómicos también.

La fotografía, aunque no se ha tratado como una actividad específica por ser un recurso esencial y necesario en los contenidos Web (incluso podría quedar englobada ya en la actividad editorial), suele presentar un alto carácter creativo, especialmente las imágenes que hacen referencia a platos gastronómicos. La fotografía suele ser recurrente en todos los casos de estudio, siendo elementos habituales las personas (participantes y equipos) y/o los platos finalizados. También las instalaciones en el caso de los restaurantes.

Por último, en relación a dicha tipología de actividades existen entre todas ellas tanto productos tangibles, como pueden ser los propios libros o incluso perfumes (vinculados con la moda), y también servicios de carácter puramente intangible como I+D, aplicaciones online o el turismo enológico.

Finalidad otras actividades creativas

\section{Gráfico 4. Finalidad otras actividades de Industrias Creativas}

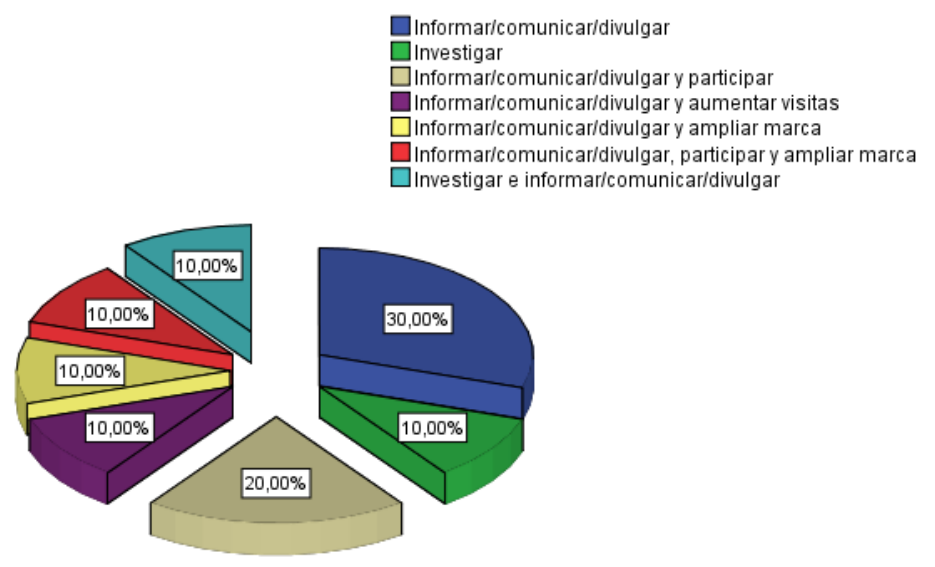

Fuente: elaboración propia 
La finalidad de estas actividades creativas es también muy diversa. Lógicamente, puesto que entre ellas el sector editorial es el predominante, el propósito de los libros y las revistas es el de proyectar una información a los lectores. En este sentido los libros pretenden presentar un contenido formativo, asociado al conocimiento. Es decir, generalmente presentan estilos de cocina y recetas. Por lo que respecta a las revistas, asociadas a los programas de televisión, intentan también acercar la actualidad de los respectivos talents shows a su audiencia. El contenido audiovisual, la pintura y las exposiciones también contribuyen a difundir una información, conocimientos y otros mensajes culinarios mediante distintas técnicas de expresión.

\section{Imagen 1. Cartel de la Película El somni del Celler de Can Roca, 2013}

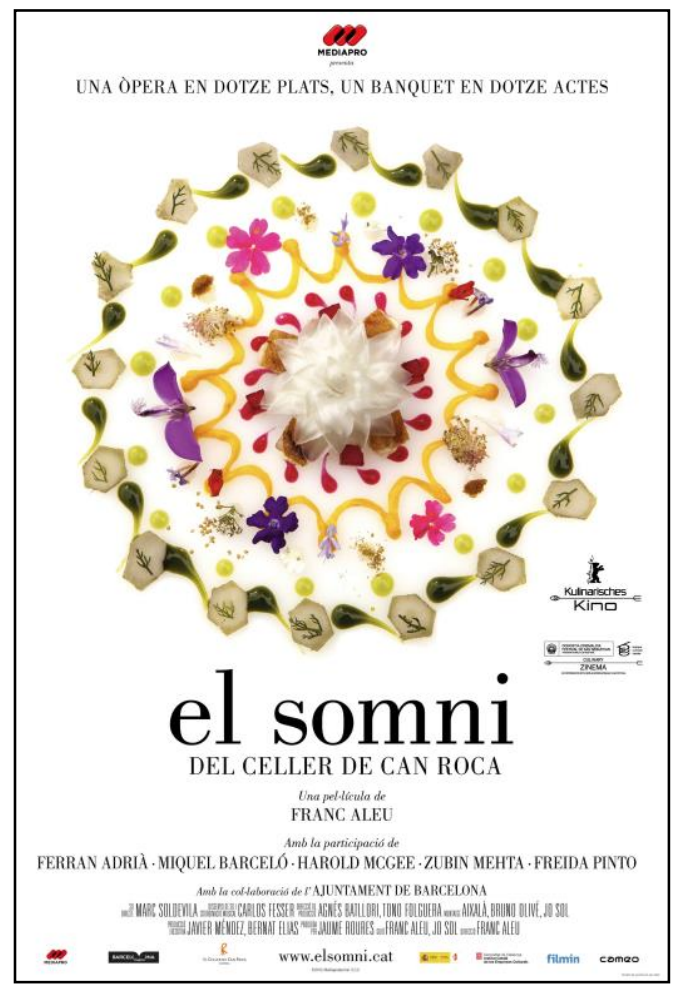

Fuente: http://www.elsomni.cat/es/el-somni/la-pelicula/

No obstante entre la amplia diversidad de actividades encontradas existen otras finalidades como fomentar la interactuación y participación a través del software específico (MasterChef o Top Chef), aumentar las visitas al restaurante mediante el turismo gastronómico enológico 
(Azurmendi), investigar en el caso de I+D en la cocina (Arzak o Akelarre), o simplemente ampliar la marca del restaurante vía el diseño productos de diversa índole y la decoración. Normalmente, dada la combinación de acciones conjuntas, se mezclan varias finalidades por cada caso de estudio.

Asimismo todas ellas persiguen, además, de alguna forma aproximar la cocina con autoría a la sociedad con el entretenimiento y evidentemente encontrar un reporte económico directo o indirecto a medio plazo. Por lo tanto, las respectivas marcas se ven favorecidas por la suma de todas las acciones y sus diversas finalidades.

Medios de promoción

Gráfico 5. Medios de promoción casos de estudio

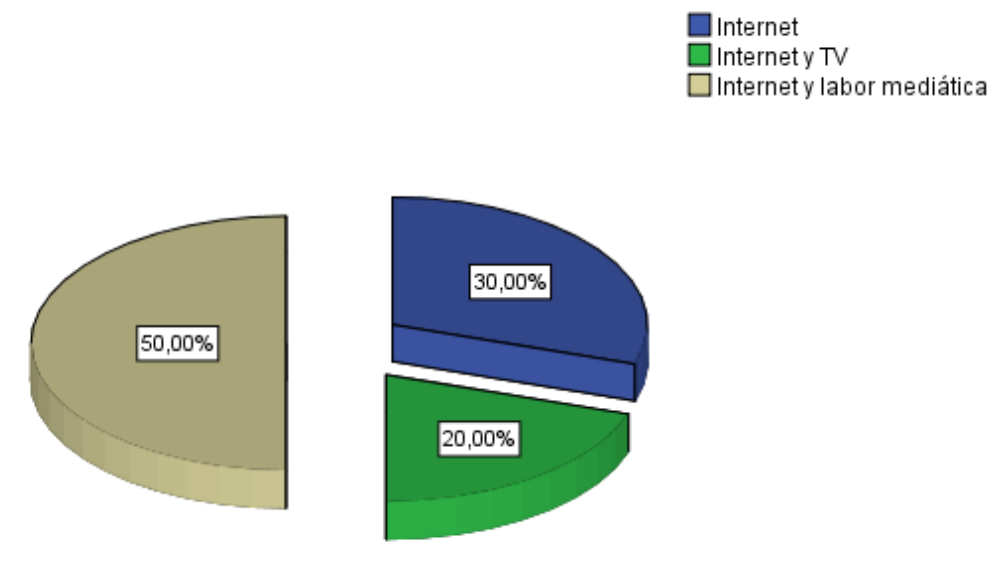

Fuente: elaboración propia

Por lo que respecta a los medios de promoción de todas las actividades, incluida la principal, existen dos tendencias. Por una parte, los programas de televisión suelen emplear dicho medio como canal de difusión. Asimismo también emplean sus respectivas Webs oficiales como medio de promoción tanto del contenido del programa en sí, de otro contenido extra como del resto de actividades adicionales.

Por su parte, los restaurantes suelen difundir su información también a través de sus Webs. Asimismo, en cinco de los casos analizados (Arzak, Azurmendi, El Celler de Can Roca, Martín Berasategui y Quique Docosta), se presentan secciones de prensa (y/o vía 
actualidad) con toda la información sobre apariciones mediáticas offline y online del restaurante o chef principal y/o material de descarga para los medios de comunicación. Aspecto que deja constancia de la difusión de su labor mediática principalmente sobre periódicos y revistas especializadas (aunque también otros medios y soportes), para promocionar su labor, aproximarla a una mayor audiencia y reforzar la imagen de marca más allá del restaurante.

Aunque de forma esporádica, algunos de los chef de dichos restaurantes han aparecido en programas tanto MasterChef como Top Chef para amplificar la repercusión de su cocina. No obstante, las Webs no suelen hacer referencia a estas apariciones.

Tienda online actividades creativas adicionales

\section{Gráfico 6. Tienda online de las actividades creativas adicionales}

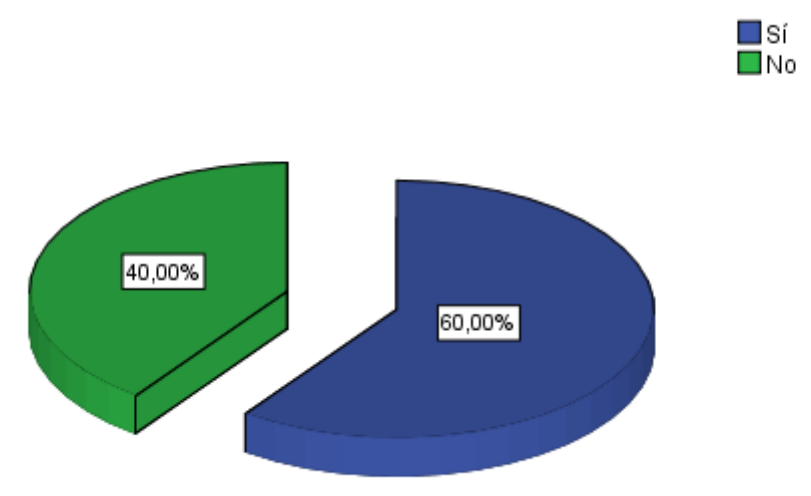

Fuente: elaboración propia

Seis de los casos de estudio (Top Chef, Arzak, Azurmendi, El Celler de Can Roca, Martín Berasategui y Sant Pau) disponen en la Web también de tienda online propia o que remite a otras plataformas de comercio online para así, poder adquirir directamente los productos resultantes de las actividades creativas adicionales. Este aspecto demuestra la adaptación del modelo de negocio a las nuevas tecnologías, especialmente ante el emergente comercio online. Una forma más de facilitar la adquisición o contratación de dichos bienes y de ampliar la actividad promocional de cada una de las actividades. 


\section{Conclusiones}

Se constata el nexo de unión entre la gastronomía y las industrias creativas en España. Los programas de televisión en torno a esta temática así como los restaurantes más premiados por la guía Michelín en España, dado su cometido y creciente dinámica creadora, no sólo forman parte de las Industrias Creativas sino que también generan otras actividades adicionales dentro del sector. Se verifica de esta forma que la gastronomía es un modelo de Industria Creativa referente en España con un constante crecimiento y buenas perspectivas de futuro.

Los programas de televisión así como los restaurantes tres estrellas Michelin difunden también su labor y cometido a través de otras actividades que conforman las Industrias Creativas. Más allá de la labor principal de emisión de contenido televisivo y la restauración, los casos de estudio analizados desarrollan otras actividades de carácter creativo que sirven para promocionar los respectivos programas y/o restaurantes, pero a su vez también para asentar su marca entre nuevos públicos. Por tanto la gastronomía, dada su versatilidad y sus particularidades, y más allá de poder incluirse en diversas actividades que conforman las Industria Creativas, se convierte en un modelo propio de dicho sector que genera a su vez, otras actividades creativas englobadas en éste.

Las actividades adicionales son de carácter multidisciplinar, aunque las relacionadas con el sector editorial adquieren mayor relevancia. Los programas de televisión, recurren habitualmente a revistas de actualidad propias, así como a la edición de libros. Por su parte los restaurantes generalmente también editan libros para difundir información de actualidad y/o gastronómica potenciando de esta forma también la marca. De esta forma el recurso editorial sirve como plataforma principal para canalizar de una forma amena y sosegada los contenidos a los receptores de interés.

Los casos de éxitos analizados, con independencia de su origen y trayectoria, se adaptan a las nuevas exigencias creativas y tendencias comerciales para poder ofrecer calidad y diferenciación significativa. MasterChef, Top Chef y los restaurantes 3 estrellas Michelín España 2014, partiendo de su cometido principal, desarrollan otras acciones promocionales. Éstas se basan en el desarrollo de actividades secundarias de carácter creativo y también mediante difusión de contenidos en antena (en el caso de los programas de televisión) y distintos medios, especialmente prensa (en el caso de los restaurantes). Todo ello, sumado al uso de las nuevas tecnologías, posibilita su éxito comercial a la vez que su adaptación a una sociedad interconectada y con poder de decisión. 
Queda patente que esta dinámica consolida la tendencia de conectar y aproximar la gastronomía hacia la sociedad del ocio y el entretenimiento, constatándose además que la gastronomía es parte importante de la sociedad. No sólo porque forma parte del acervo cultural de un territorio y sus costumbres, sino porque intenta ofrecer algo distinto a la vez que atractivo a un amplio y heterogéneo grupo social, que no se conforma ya con adquirir productos o servicios, sino que demanda realmente poder disfrutarlos y saborearlos.

Por lo tanto, y en relación a las tres premisas de partida, se confirma que la gastronomía a través los programas de televisión y los restaurantes 3 estrellas Michelín en España forman parte de las Industrias Creativas. Es evidente que las particularidades que conforman los casos de estudio analizados permiten su incorporación a dicho sector.

Asimismo estos casos desarrollan otra serie de actividades adicionales que también quedan englobadas dentro del sector. El estudio realizado corrobora que tanto los formatos televisivos como los restaurantes desarrollan otra serie de acciones secundarias 0 adicionales, también con valor simbólico, que refuerzan y promocionan la principal actividad genérica así como a la propia marca. Dichas actividades, a su vez, representan un carácter multidisciplinar y multiformato, aspecto que deja constancia de la amplia variedad y originalidad para aproximar la gastronomía a la sociedad del entretenimiento.

En definitiva, la gastronomía ha dejado de ser un motor económico vinculado a sectores tradicionalmente estáticos y se reinventa creativamente para convertirse en un paraguas de contenido cuyo objetivo es responder a las necesidades de ocio y entretenimiento, mediante la aplicación no solo de la lógica de la mercantilización sino también de las propias lógicas creativas. Todo ello, bajo una economía creativa que sustenta el desarrollo y la evolución tanto del producto cultural como del propio modelo de negocio y del engranaje que envuelve el entorno gastronómico global.

\section{Discusiones}

Se constata, pues, que la gastronomía y las distintas formas para aproximarla a la sociedad del entretenimiento mantienen un fuerte vínculo con las Industrias Creativas en España. Tanto es así que los modelos analizados (entiéndase los programas de televisión y los restaurantes así como el resto de actividades generadas), se pueden considerar ya como parte importante de dicho sector. 
De esta forma parece pertinente y lógico pensar que esta tendencia irá cada vez más en aumento. Una evolución que, respaldada por el gran prestigio de la cocina española y sustentada también sobre el éxito de los programas de cocina en las últimas décadas, parece transformar a la gastronomía como una fuente incesante de creatividad, negocios y entretenimiento de diversa índole. Por todo ello, se abren nuevos frentes que precisarán de otros estudios que permitan determinar el papel que tendrá la gastronomía en la sociedad y en la economía del futuro. Entre ellos, por ejemplo, las aportaciones económicas de cada actividad al total del negocio, la comunicación a través de las redes sociales, aplicaciones móviles y su difusión internacional vía marketing Web, el papel de los chef como generadores de opinión, etc.

En definitiva, la gastronomía continúa dando un salto cualitativo y distintivo para consolidarse en la economía creativa mediante fórmulas novedosas que no sólo convierten en elemento sociocultural el entretenimiento sino también en modelos que generan otras ideas y, éstas a su vez, en rentabilidad económica.

\section{Bibliografía}

British Council (2010). Mapping the Creative Industries: A Toolkit. Recuperado de http://www.britishcouncil.org/mapping the creative industries a toolkit 2-2.pdf

Boix, R. y Lazzeretti, L. (2011). Las industrias creativas en España: una panorámica. Investigaciones Regionales. 22 - Páginas 181 a 206 Sección Panorama y Debates

Dossier de prensa Guía Michelin. España y Portugal (2014). Recuperado de www.michelin.es/content/pdf/quia michelin v2.pdf

Garnham, N. (2005). From cultural to creative industries. An analysis of the implications of the "creative industries" approach to arts and media policy making in the United Kingdom. International Journal of Cultural Policy, Vol. 11, No. 1

Hidalgo-Marí, T. y Segarra-Saavedra, J. (2014). Televisión y gastronomía. Análisis histórico de la programación televisiva desde una perspectiva publicitaria. Pensar la Publicidad. Revista Internacional de Investigaciones Publicitarias, 7(2). [Artículo aceptado pendiente de publicación en el próximo número].

Ketchum, C. (2005): The Essence of Cooking Shows: How the Food Network Constructs Consumer Fantasies. Journal of Communication Inquiry, 29, pp. 217-234. 
Morcillo, P. y Alcahud López, M. C. (2005). Creatividad que estás en los cielos... Revista de Investigación en Gestión de la Innovación y Tecnología. Fomento de la Innovación Tecnológica. Número 30.

Olivares F. (2012). Rebelión en las marcas. Madrid: LID Editorial Empresarial. Pérez, C. C. y Salinas, G. (2008). Valoración y evaluación de marcas. Ediciones Deusto.

Pérez C.C. y Salinas G. (2008). Valoración y evaluación demarcas. Deusto: Ediciones Deusto.

Rodríguez-Monteagudo, E. e Hidalgo-Marí, T. (2013). Radiografía de la Universidad de Alicante a través de las noticias emitidas en el Diario Información. Revista Mediterránea de Comunicación, vol. 4(1), pp145-167. Recuperado de http://www.mediterraneacomunicacion.org/Mediterranea/article/view/47/136

Rodríguez, R.; Tur, V. y Olivares, F. (2010). Industrias creativas: novedades, objeciones y perspectivas. Actas II Congreso Internacional Latina de Comunicación Social. Universidad de la Laguna, Diciembre. Recuperado de http://www.revistalatinacs.org/10SLCS/actas 2010/37Raul.pdf

UNCTAD (2010). Economía Creativa Informe 2010. Recuperado de http://unctad.org/es/Docs/ditctab20103 sp.pdf

UE (2010). Libro Verde: Liberar el potencial de las Industrias Culturales y Creativas. COM (2010)183 final (Bruselas, 27-4-2010).

UNESCO (2006). Comprender las industrias creativas. Las estadísticas como apoyo a las políticas públicas.

Recuperado

de http://portal.unesco.org/culture/en/files/30850/11467401723cultural stat es.pdf/cultural stat es.pdf

William Reed Business Media (2014). The World's 50 Best Restaurants. Recuperado de http://shop.william-reed.com/store/products,worlds-50-best-restaurants-guide 2552.htm

\section{Webs de restaurantes y programas televisivos seleccionados:}

- Web Master Chef. Recuperado de http://www.rtve.es/television/masterchef/ (consulta junioseptiembre 2014).

- Web Master Chef Junior. Recuperado de http://www.rtve.es/television/masterchef-junior/ (consulta junio-septiembre 2014).

- Web Top Chef. Recuperado de http://www.antena3.com/programas/top-chef/ (consulta junioseptiembre 2014).

- Web Restaurante Akelarre. Recuperado de http://www.akelarre.net/public home/ctrl home.php (consulta junio-septiembre 2014).

- Web Restaurante Arzak. Recuperado de http://www.arzak.info/ (consulta junio-septiembre 2014).

Facultad de Ciencias de la Información - Universidad de La Laguna

Avenida César Manrique, s/n; Campus de Guajara

38071 La Laguna, Tenerife (Islas Canarias - España) 
- Web Restaurante Azurmendi. Recuperado de http://www.azurmendi.biz/ (consulta junioseptiembre 2014).

- Web Restaurante El Celler de Can Roca. Recuperado de http://cellercanroca.com/index.htm (consulta junio-septiembre 2014).

- Web Restaurante Martín Berasategui. Recuperado de http://www.martinberasategui.com/es/inicio (consulta junio-septiembre 2014).

- Web Restaurante Quique Dacosta. Recuperado de http://www.quiquedacosta.es/ES/inicio (consulta junio-septiembre 2014).

- Web Restaurante Sant Pau. Recuperado de http://www.ruscalleda.com/es

- Web Michelín. Recuperado de http://www.michelin.es/ (consulta mayo 2014).

- Web 50 Gastro Economy. Recuperado de http://www.gastroeconomy.com/ (consulta mayo 2014).

- Web Pesadilla en la Cocina. Recuperado de http://www.lasexta.com/programas/pesadilla-en-lacocina/programa/ (consulta septiembre 2014).

- Web TVE A la Carta. Recuperado de http://www.rtve.es/alacarta/videos/con-las-manos-en-lamasa/ (consulta septiembre 2014).

- Web Restaurante Diverxo. Recuperado de http://diverxo.com/ (consulta octubre 2014)

\section{Forma de citar este artículo en bibliografías}

RODRÍGUEZ-MONTEAGUDO, E.; HIDALGO-MARÍ, T. y SEGARRA-SAAVEDRA, J. (2014): La gastronomía como producto de entretenimiento. Análisis de restaurantes y programas culinarios de éxito en España desde una perspectiva creativa, en Revista PANGEA, 5, páginas 145 a 157. Red Académica Iberoamericana de Comunicación. Recuperado el _ de de 2 de: http://www.revistapangea.org 